\title{
EL MALTRATO A LOS ANIMALES: \\ UN PROBLEMA QUE CUESTIONA NUESTRA PROPIA RACIONALIDAD
}

\section{Rodolfo Sánchez Zepeda.}

Juez Federal (México D.F.)

El ser humano no vive sólo en este planeta, todo lo contrario.

Todas las especies, animales y vegetales, tienen, al igual que el hombre, un lugar en este mundo en el que todos hemos sido creados, y por lo tanto, como el hombre, una razón de su existencia, una razón propia como ser vivo y una razón ajena como parte de este universo.

En cuanto al primer aspecto, ya lo señalaba Aristóteles, al declarar que todo organismo vivo tiene un bien propio al cual se dirige en el proceso de su desarrollo para la obtención de un fin, lo que el estagirita denominaba telos.

En cuanto a la razón ajena, los animales y las plantas se conforman como parte de un ecosistema que conduce a un equilibrio natural que favorece a todas y cada una de las especies que habitamos en este planeta. La conformación de las sociedades por la mano del hombre, ha buscado para sí la creación de un espacio idóneo para su propio desarrollo, en el que en el mejor de los casos se vea acompañado de otros seres humanos pero también de otros animales no salvajes, rodeado de naturaleza apta para la vida del hombre.

Por lo tanto, el estado natural del hombre, donde mejor se produce su desarrollo físico y mental, no es aislado, sino que está íntimamente vinculado en su relación con otros seres humanos y con parte de la naturaleza, tanto animal como vegetal.

El ser humano es el ser vivo dotado de las más altas cuotas de racionalidad, lo que le sitúa en un estado de superioridad frente al resto de los seres vivos. Esta afirmación nos ofrece un punto de partida esencial y dirige de manera importante el planteamiento que utilizaremos en este trabajo, cuyo objeto no es otro sino defender el derecho de los animales a no ser maltratados.

Si esta superioridad del hombre frente a los animales está basada en la racionalidad, entonces será la racionalidad el único fundamento práctico que deba regir nuestro trato y comportamiento hacia los animales. Al afirmar que el hombre se sobrepone al resto de los 
animales (y vegetales) porque es racional, no puede justificarse nuestro dominio sobre las especies desde la irracionalidad, es decir, desde la crueldad, la violencia injustificada o la fuerza bruta, todas enemigas de la racionalidad.

Desde que el hombre implantó en las sociedades políticas, el principio de la racionalidad en la época del Iluminismo como eje de la vida social, política, económica o religiosa, se equiparó la razón con una convivencia pacífica entre todos los hombres, el control de la violencia legal, la eliminación del mal por el mal y la búsqueda de la supresión absoluta de la fuerza arbitraria e injusta; es decir, eliminar de nuestra vida y de nuestro entorno el dolor y el sufrimiento que no esté debidamente justificado en aras de la búsqueda de un bien mayor.

A partir de estas ideas básicas, el hombre del iluminismo diseñó un sistema moral o ético sobre el cual dirigir el comportamiento externo del hombre.

Somos conscientes de que el racionalismo, tal como fue entendido durante el Iluminismo, no tuvo en cuenta el dolor y sufrimiento de los animales, así como tampoco el de las mujeres (en ciertos aspectos de su vida), el de los hombres de raza negra o el de los enfermos mentales, todos ellos seres vivos, conquistas estas últimas que no se darían sino hasta varios siglos después.

Pudiera haber algún lector que se pueda escandalizar por meter en el mismo saco a mujeres, personas de raza negra y enfermos con los animales; sin embargo, esta idea no es descabellada puesto que todos ellos comparten una esencia física que les hace a todos acreedores de unos derechos y, por lo tanto, de un comportamiento concreto hacia ellos.

Cuando comenzaron a redactarse las primeras declaraciones en derechos humanos, encontramos de fondo un planteamiento de tipo natural del hombre (razón de ello que en los primeros momentos se refiriera a los derechos humanos como derechos naturales).

El hombre era acreedor de unos derecho naturales por cuanto el hombre es un ser natural. Desde que la ciencia es ciencia se ha descrito al hombre como un ser animal y espiritual, y será a partir de este planteamiento que justifiquemos para efectos de este artículo, considerar en una misma tipología a los hombres, mujeres, personas de raza negra o a los enfermos mentales, por seguir el ejemplo expuesto.

A partir de la composición del hombre como ser animal y espiritual se derivan una serie de derechos, los que englobamos como "derecho humanos". 
En su faceta animal, nos referimos al hombre como ser vivo y biológico, la racionalidad nos prohíbe el uso de la fuerza injustificada que produce el dolor por el dolor, el sufrimiento, y nos obliga a promover el bienestar y, en última instancia, la supervivencia; en cuanto al aspecto espiritual, los derechos del hombre se dirigían a todo aquello que nos dotaba de dignidad, como el honor, la propiedad, el trabajo, los derechos políticos, etcétera.

Los animales no contienen, o no se ha demostrado fehacientemente, que contengan el aspecto espiritual del hombre, pero no es necesario demostrar que contienen la parte “animal" del hombre. Es por ello que el animal, como tal, poseedor de un telos propio, basado en la ausencia del dolor, en la búsqueda del bienestar propio y en su supervivencia, deba estar dotado de esos "derecho naturales", que ya no se restringen al hombre blanco, sino que igualmente son debidos al resto de especies que, como el hombre blanco, tienen la facultad de sufrir el dolor y regocijarse en el bienestar de su lucha por la supervivencia (recuérdese cómo en otras épocas se justificaba el maltrato a la mujer o a los esclavos).

El respeto a estos derechos derivados de la esencia animal, configura lo que los textos legales refieren como el respeto a la "dignidad" de los animales.

A partir de estos parámetros (esencia animal y espiritual), el hombre del iluminismo rechazaba la violencia (si bien únicamente contra la de sus idénticos caracteres biológicos), la que únicamente se podía justificar para evitar el dolor o sufrimiento inminente y directo (lo que en derecho se llama la legítima defensa o el estado de necesidad).

Más allá de ello, la violencia por la violencia es injustificada. Traslademos estos fundamentos al comportamiento con los animales domésticos.

El animal doméstico es un animal que, como tal, posee el telos animal, es decir, huye del dolor, busca el bienestar y su supervivencia. Pero además, el animal doméstico es más vulnerable que el resto de los animales, por cuanto que fue elegido por el hombre para vivir cerca de él, permanentemente.

Sin embargo ¿cómo se ha comportado el hombre para con estos animales? La paradoja radica en que justamente es el hombre el único animal que ejerce crueldad sobre los animales domésticos, en particular, y los animales en general, y al mismo tiempo es el único capaz de frenarla.

Y nos referimos a crueldad como expresión de la violencia por la violencia, pues los mismos animales entre ellos no actúan de esta forma, ya que sólo se atacan por razones de 
supervivencia pero no con fines de infligir dolor innecesario entre ellos (salvo excepciones que pudiesen estar documentadas).

La racionalidad del hombre le impone derechos, pero sobre todo le ha impuesto deberes y responsabilidades, ¿qué responsabilidades ha tomado el hombre con respecto a la protección del telos de los animales domésticos?, ¿qué medidas a tomado el hombre con relación a la crueldad inferida a estos animales indefensos, que necesitan de la "racionalidad" del hombre para su supervivencia y bienestar?

La racionalidad, se dijo al principio de este trabajo, es el único eje que debe guiar nuestra conducta para con los animales, lo cual cumplimos respetando su telos, la no violencia injustificada y el rechazo de la crueldad para con ellos. Estas han de ser las máximas del comportamiento racional hacia los animales. No hay otro.

El utilitarismo, si bien avanzó en la consideración de los animales como seres con derechos, al considerarlos seres que sufrían y que padecían el dolor al igual que nosotros, no obstante su máxima ("buscar el mayor bien posible para el mayor número posible de individuos"), podía justificar el maltrato a animales en aras a un beneficio mayor de los individuos.

La teoría demostró ser insuficiente. ¿Puede justificarse mantener a las gallinas encerradas de forma permanente en minúsculas celdas donde no conocen la luz del sol, ni pueden desplazarse y estirar su pequeños músculos, o picar la tierra?

Nos preguntamos, ¿por qué los huevos son más ricos cuando la gallina disfruta de su libertad en la granja? ¿o la carne de pollo cuando éstos disfrutan de una vida libre y adecuada en su granja?

Todo tiene un sentido y un por qué que está relacionado con la propia naturaleza a la que ellos pertenecen. Existen teorías que pretenden justificar esta crueldad contra los animales, ya sean gallinas o pollos, pero también cerdos o vacas bajo la premisa de que a falta de estos sistemas la población se moriría de hambre.

Esta afirmación no puede ser más falsa. Todos los días los grandes supermercados tiran a la basura toneladas de comida que no se ha vendido. Más bien el que se muere de hambre, en ausencia de estos irracionales sistemas, es una forma de capitalismo voraz e insaciable que ofrece más a la población de lo que ésta puede demandar, pues no se basa su actuación en la satisfacción de la demanda natural de las necesidades del hombre sino en el 
consumo irracional, la venta desesperada, cuyo única meta es el enriquecimiento exorbitado de las grandes superficies, a costa de convertir al ciudadano en objeto de consumo, y al animal en objeto de producción.

Esta es una forma de crueldad del mal por el mal, del mal injustificado e irracional. Por ello, un análisis de la teoría del utilitarimo no podría defender este tipo de uso animal, por cuanto los beneficiados son unos pocos, justamente los dueños de las fábricas deshonrosas de producción y los grandes almacenes que los venden y promueven.

Esta es sólo una forma de crueldad contra los animales en la actualidad ya entrados en el siglo XXI. El maltrato a los animales que tenemos en la casa se manifiesta de otras formas.

¿El maltrato por el maltrato?, ¿la crueldad por el puro beneficio de observar el sufrimiento del otro? Cuando se trata de una cuestión entre seres humanos, lo calificamos como una desviación de la mente. ¿Y cuando es contra los animales? Lo calificamos muchas veces de tradición, como la caza del zorro o la quema de perros, entre otras.

Nos olvidamos que los animales craneales tienen un telos, que como el nuestro, está basado en la capacidad de sufrir y gozar, y que nosotros como seres racionales estamos llamados a protegerlo.

La protección legal contra el maltrato de los animales, es la forma que el hombre racional tiene de frenar y reprimir la violencia en nuestras vidas. Si educamos a nuestros hijos en que la crueldad contra todo ser viviente es malo en sí mismo, estamos transmitiendo un mensaje claro, que calará mejor en las mentes que aún se están desarrollando y conformando.

Enseñar a un niño que está mal que pegue a su primo pero bien maltratar a un animal, el mensaje le llega distorsionado, y finalmente no cumplirá el papel que se pretende, que es alejar al niño de la violencia en términos absolutos (con la única excepción de la legítima violencia, lo cual es, además, puro instinto natural).

La realidad nos ha enseñado que los sentimientos de amor, compasión, odio o frustración no se compartimentalizan, sino que se extienden a nuestras relaciones con los demás. Cuando una persona está contenta, puede llegar a hablar con los animales, cuando está furiosa suele desplegar su furia contra todo lo que ve. Si al niño se le enseña que puede 
maltratar a un animal, raro sería que con el tiempo no maltrate a un ser humano, pues ya trae la semilla de la violencia consigo.

Como señalábamos anteriormente, hay una razón universal en todos y cada uno de nosotros, todos tenemos nuestro papel y nuestro por qué, somos parte de un ecosistema que solo funcionará adecuadamente si lo regimos por la racionalidad, con amor y respeto a todo lo que nos rodea.

Ahora bien, a pesar de la importancia que tiene para la sociedad erradicar la violencia de cualquier tipo, y especialmente la violencia contra seres indefensos con los que convivimos diariamente y que se convierten en ejemplo público para nuestros jóvenes, las autoridades en México han menospreciado la profundidad del tema y las consecuencias que tiene no erradicar este tipo de brutalidad en una sociedad ya de por sí violenta.

Ni siquiera el suceso ocurrido en Nayarit, México, en el año 2010, en el cual tres jóvenes subieron a internet un video en el que aparecían torturando y sacrificando a un perro callejero (ni doméstico ni silvestre ${ }^{1}$ ), no ha producido los efectos deseados por las organizaciones protectoras de animales. Al calor de lo sucedido, y presionado por la respuesta no sólo nacional sino internacional que provocó el video, produciéndose simultáneas manifestaciones en contra del maltrato animal en diversas latitudes del planeta, las autoridades del Estado de Nayarit prometieron cambios a una deficiente legislación contra este tipo de actos. La situación, no obstante, es la misma.

Al igual que Nayarit, otros estados mexicanos como San Luis de Potosí2, Michoacán ${ }^{3}$ o Campeche ${ }^{4}$, contienen en su legislación una política discriminatoria al proteger únicamente ciertos tipos de animales. En contraposición, sólo el estado de Veracruz $^{5}$, o el Distrito Federal $^{6}$, incluyen en su protección a animales callejeros, presentando una política contra la violencia más integral y coherente. Hay que tener

\footnotetext{
${ }^{1}$ La ley de Protección de animales de 16 de diciembre de 2006 no contempla a los animales callejeros como sujetos de protección.

${ }^{2}$ La ley de Protección de animales del Estado de San Luis Potosí de fecha 14 de enero de 2004, en su artículo $4^{\circ}$ establece que "Al mencionarse en esta ley el concepto animal, se debe entender a todas aquellas especies y subespecies clasificadas dentro de este reino, destinadas para cualquier uso y aprovechamiento por el hombre".

${ }^{3}$ La ley de Protección de animales del Estado de Michoacán de día 11 de julio de 1988, únicamente hace referencia a animales domésticos y silvestres.

${ }^{4}$ La ley de Protección de animales del Estado de Campeche de 3 de diciembre de 2003, incluye sólo a domésticos y de cría, en el sentido analizado, dejando fuera a los abandonados.

${ }^{5}$ La ley de Protección de animales del Estado de Veracruz de 5 de noviembre de 2010.

${ }^{6}$ La ley de Protección de animales del Distrito Federal de 26 de febrero de 2002.
} 
presente que, en la misma línea que los anteriores, no se prohíben, por ejemplo, las peleas de gallos.

El problema es no afrontar el problema desde una filosofía integral de los animales como seres vivos, a partir de un fundamento racional que obliga al hombre a un comportamiento debido con respecto a cualquier tipo de animales, ya sean de carga, circenses, abandonados o domésticos.

¿No tienen los hombres abandonados, vagabundos o los enfermos, los mismos derechos que el pudiente y sano? La razón está no en las características externas o de "uso" a los que sirve la persona, sino en la esencia que todo hombre contiene en sí mismo, como ser animal racional.

La misma argumentación habrá de extenderse a los animales, los cuales poseedores de esa esencia animal, como vimos, dotadora de unos derechos, los sitúa a todos en una misma línea legal, como acreedores de los mismos derechos, atendiendo a sus propias características, en atención a su particular telos.

La legislación mexicana falla en atender el problema desde esta fundamentación, incurriendo en discriminaciones injustas y arbitrarias entre los animales, lo que lleva a pensar que esas normas de protección tienen como destino, más el interés del hombre que al propio animal como tal.

Por otro lado, si atendemos a las sanciones que la ley hace atribuir a los casos de maltrato, podemos observar que éstas no tienen un mínimo efecto disuasorio. En primer lugar, las consecuencias son únicamente económicas (no existe la posibilidad de cerrar un comercio o centro recreativo por este motivo, salvo en raras excepciones como en Veracruz, y en ningún caso corresponde una pena de cárcel), y en segundo, la multa máxima en caso de violencia excesiva no llega a 4,000 pesos, la cual puede ser fácilmente eludida por falta de recursos.

Ciertamente, existe una posibilidad de detención no superior a 24 horas, lo que no varía esta situación que planteamos. Estamos muy lejos, como sucede en otros países como Estados Unidos o el Reino Unido, de criminalizar este tipo de actos y convertirlos en meritorios de altas multas y hasta pena de cárcel.

Desgraciadamente México no se encuentra entre los países que han mostrado una alta "racionalidad" en este tema. México no ha tenido la sensibilidad ni la inteligencia para 
darse cuenta de las consecuencias desastrosas que tiene el emitir dos mensajes paralelos y contradictorios en su esencia, manteniendo, por un lado, como "legal" la violencia contra los animales, y prohibiendo por otra, la violencia entre personas.

Un mensaje serio, contundente, coherente y de carácter general contra todo tipo de violencia y crueldad injustificada, ayudaría a este país en su camino hacia la tan deseada paz social. 